\title{
Qualidade da água utilizada na irrigação de produtos orgânicos: o caso de um polo agrícola em Paço Lumiar/MA
}

O Polo Agrícola Hort Canaã/MA pratica a agricultura familiar orgânica e irriga as suas culturas com água proveniente de um poço artesiano localizado no seu próprio terreno, tendo em vista que, a água de irrigação é o maior fator de influência na quantidade de doenças em uma lavoura, faz-se necessário estudar a qualidade das águas utilizadas para irrigação, principalmente aquelas que irrigam produtos orgânicos, que precisam está livre de contaminantes para não prejudicar a produção. Diante disso, este trabalho objetivou avaliar a qualidade da água subterrânea para fins de irrigação utilizada no Polo Agrícola Hort Canaã da Vila Residencial Nova Canaã localizado no município de Paço do Lumiar/MA. Os parâmetros avaliados foram: pH, dureza total, cálcio, magnésio, alcalinidade e parâmetros microbiológicos. Os resultados obtidos mostraram que com exceção do $\mathrm{pH}$, as demais variáveis não apresentaram risco de dano ao sistema de irrigação e a qualidade da água irrigada.

Palavras-chave: Água de irrigação; Água subterrânea; Agricultura orgânica.

\section{Quality of water used for irrigation of organic products: the case of an agricultural pole in Paço Lumiar/MA}

The Hort Canaã/MA Agricultural Pole practices organic family farming and irrigates its crops with water from an artesian well located on its own land, considering that irrigation water is the biggest influence factor in the amount of diseases in a crop, it is necessary to study the quality of the water used for irrigation, especially those that irrigate organic products, which need to be free of contaminants to avoid harming production. Therefore, this study aimed to assess the quality of groundwater for irrigation purposes used in the Hort Canaã Agricultural Complex of Vila Residencial Nova Canaã located in the municipality of Paço do Lumiar/MA The evaluated parameters were: $\mathrm{pH}$, total hardness, calcium, magnesium, alkalinity and microbiological parameters. The results obtained showed that, with the exception of $\mathrm{pH}$, the other variables did not present a risk of damage to the irrigation system and the quality of the irrigated water.

Keywords: Irrigation water; Subterranean water; Organic agriculture.

Topic: Oceanografia Física, Química, Geológica, Biológica

Reviewed anonymously in the process of blind peer.
Received: $12 / 12 / 2019$

Approved: 21/02/2020
Jeferson Botelho Rodrigues

Universidade Vale do Rio Verde, Brasil

http://lattes.cnpq.br/9702846379230129

http://orcid.org/0000-0001-6371-7912

botelhojef@gmail.com

Débora Danna Soareas da Silva (it)

Instituto Federal do Ceará, Brasil

http://lattes.cnpq.br/8673315906922148

http://orcid.org/0000-0002-8239-655X

dannasilva94@gmail.com

Stephanie Jael Negrão de Freitas

Universidade Federal do Pará, Brasil

http://lattes.cnpq.br/1432769722634758

http://orcid.org/0000-0001-9917-5342

negro.sthepanie@gmail.com

\author{
Ana Carla Leite Carvalho Cabral (DD) \\ Universidade da Amazônia, Brasil \\ http://lattes.cnpq.br/6538382004505294 \\ http://orcid.org/0000-0002-1735-1320 \\ calincarvalho@gmail.com \\ Greicy Kelly Pfeiff (iD \\ Universidade Federal do Pará, Brasil \\ http://lattes.cnpq.br/3184434235363982 \\ http://orcid.org/0000-0002-4713-0617 \\ greicypfeiff@gmail.com \\ Islia Lima de Sousa Amorim (iD) \\ Universidade do Estado do Pará, Brasil \\ http://lattes.cnpq.br/2161191307542899 \\ http://orcid.org/0000-0001-6629-5794 \\ islia.amorimeng@gmail.com
}

\section{Referencing this:}

RODRIGUES, J. B.; SILVA, D. D. S.; FREITAS, S. J. N.; CABRAL, A. C. L. C.; PFEIFF, G. K.; AMORIM, I. L. S.. Qualidade da água utilizada na irrigação de produtos orgânicos: o caso de um polo agrícola em Paço Lumiar/MA. Nature and Conservation, v.13, n.1, p.16-21, 2020. DOI: http://doi.org/10.6008/CBPC2318-2881.2020.001.0003 


\section{INTRODUÇÃO}

Questões acerca da quantidade e qualidade das águas tem se tornado uma preocupação constante, visto que a escassez e a degradação dos mananciais estão cada vez mais evidentes (MENDES, 2008). Enfatizase que, a quantidade e qualidade da água são de fundamental importância para a saúde e o desenvolvimento das sociedades (FROEHNER et al., 2008).

A degradação da qualidade da água vem acarretando prejuízos direto na sua utilização, restringindo ainda mais seus usos múltiplos (LIMA, 2001; SILVA et al., 2008). Assim, toda água destinada ao abastecimento humano, recreação, irrigação, entre outras atividades, devem atender padrões de qualidade, parâmetros microbiológicos, físicos e químicos, que garantem que o consumo ou o uso da água seja inofensivo à saúde das populações (SILVA et al., 2008; ENDLER et al., 2013).

Com visto, garantir a qualidade da água na irrigação é de suma importância para a proteção da saúde. Contudo, na maioria das propriedades rurais a água utilizada para tal finalidade não possui tratamento prévio, podendo vir a ser uma fonte potencial de enteropatógenos para o vegetal que será irrigado (OLIVEIRA et al., 1992; PACHECO et al., 2002; ENDLER et al., 2013).

Logo, a qualidade da água é um aspecto que deve ser considerado na irrigação, pois dependendo das suas características físico-químicas e biológicas, o seu uso pode se tornar limitado ou inviabilizado. Os principais parâmetros de qualidade da água que podem afetar direta ou indiretamente o sistema de irrigação e a qualidade da água irrigada são: pH, ferro total, magnésio, cálcio, dureza, bactérias e algas (NAKAYAMA et al., 1986; AYERS et al., 1999).

Tendo em vista que, a água de irrigação é o maior fator de influência na quantidade de doenças em uma lavoura, faz-se necessário estudar a qualidade das águas utilizadas para irrigação, de maneira mais especial aquelas que irrigam produtos orgânicos, que precisam está livre de contaminantes para não prejudicar sua produção, visto que não usam defensivos durante o cultivo. Sendo assim, este trabalho objetiva avaliar a qualidade da água subterrânea para fins de irrigação utilizada no Polo Agrícola Hort Canaã da Vila Residencial Nova Canaã localizado no município de Paço do Lumiar/MA.

\section{MATERIAIS E MÉTODOS}

\section{Área de estudo}

O polo agrícola Hort Canaã, está localizado na zona rural do município de Paço do Lumiar/MA (povoado Pindoba), ( $2^{\circ} 31^{\prime} 55^{\prime \prime}$ S, $44^{\circ} 06^{\prime} 28^{\prime \prime}$ ), possui cerca de 56 ha e, desde 2009, é utilizado pela população afetada pela instalação da Usina Termelétrica Itaqui, da ENEVA. Atualmente o polo atende à necessidade das 20 famílias e nele se pratica a agricultura familiar orgânica.

No polo a água utilizada para fins de irrigação dos produtos cultivados é proveniente de um poço artesiano, o sistema de irrigação é automatizado e cronometrado, a água é extraída de um poço e direcionada para uma cisterna e depois canalizada para as plantações através de uma bomba, que distribui água no tempo regulamentar de 30 minutos para cada área. Dentre as principais culturas cultivadas, destacam-se: as 
leguminosas, folhagens, ervas medicinais; além de plantação de mamão, maracujá, cupuaçu, cebolinha, macaxeira, feijão e banana.

\section{Procedimentos experimentais}

Para a análise da qualidade da água utilizada na irrigação dos produtos orgânicos, foram coletadas 02 amostras de $500 \mathrm{~mL}$ de água, as amostras foram armazenadas em frascos plásticos, tipo PET, previamente descontaminados. A coleta das amostras aconteceu no dia 13/09/2017 às 08:25 horas e, em seguida, estas foram levadas a laboratório.

Todas as atividades que envolveram a coleta e a preservação das amostras foram procedidas de acordo com o "Guia de coleta e preservação de amostras de água" da CETESB, estabelecido em 1977. As análises efetuadas seguiram a metodologia proposta pelo Standard Methods (APHA, 1998) e foram realizadas no Laboratório de Físico-química de Alimentos e Água da Universidade Estadual do Maranhão (UEMA) no mesmo dia da coleta.

Foram analisados os seguintes parâmetros físico-químicos e biológicos: cálcio, magnésio, dureza total, alcalinidade em $\mathrm{OH}$-, alcalinidade em $\mathrm{CO}_{3-\text {, }}$ alcalinidade em $\mathrm{HCO}_{3-\text {, }}$ alcalinidade total, cloretos $(\mathrm{Cl}-), \mathrm{pH}$, coliformes totais, E. coli e bactérias heterotróficas, importantes para avaliar a qualidade da água. Posteriormente, foi verificado os limites de restrição ao uso da água para consumo humano estabelecidos pelo Ministério da Saúde por meio da Portaria de Consolidação 5/2017, Anexo XX, apresentados no quadro 1.

Quadro 1: Padrões estabelecidos pelo Ministério da Saúde.

\begin{tabular}{|l|l|l|}
\hline Parâmetro & Valor máximo permitido (VMP) & Unidade \\
\hline Cálcio & $\mathrm{NC} *$ & $\mathrm{mg} / \mathrm{L}$ \\
\hline Magnésio & $\mathrm{NC}$ & $\mathrm{mg} / \mathrm{L}$ \\
\hline Dureza total & 500 & $\mathrm{mg} / \mathrm{L}$ \\
\hline Alcalinidade em OH- & $\mathrm{NC}$ & $\mathrm{mg} / \mathrm{L}$ \\
\hline Alcalinidade em CO $3-$ & $\mathrm{NC}$ & $\mathrm{mg} / \mathrm{L}$ \\
\hline Alcalinidade em $\mathrm{HCO}_{3}$ & $\mathrm{NC}$ & $\mathrm{mg} / \mathrm{L}$ \\
\hline Alcalinidade total & $\mathrm{NC}$ & $\mathrm{mg} / \mathrm{L} \mathrm{CaCO} 3$ \\
\hline Cloretos (Cl-) & 250 & $\mathrm{mg} / \mathrm{L}$ \\
\hline pH & entre 6,0 e 9,5 & - \\
\hline Turbidez & 5,0 & $\mathrm{UT}$ \\
\hline Coliformes totais & Ausência em $100 \mathrm{~mL}$ & $\mathrm{~mL}$ \\
\hline E. coli & Ausência em $100 \mathrm{~mL}$ & $\mathrm{~mL}$ \\
\hline Bactérias heterotróficas & máx. 500 & $\mathrm{UFC}$ \\
\hline & & \\
\hline
\end{tabular}

Fonte: Brasil (2017)

*NC = Não Consta na Portaria de Consolidação 5/2017, anexo XX do Ministério da Saúde.

$* *$ UFC = Unidade Formadora de Colônia.

\section{RESULTADOS E DISCUSSÃO}

Os resultados obtidos para as análises físico-químicas da água subterrânea utilizada para irrigação no polo agrícola Hort Canaã encontram-se no quadro 2. Com relação ao resultado físico-químicos, nota-se que o valor de pH não está dentro do parâmetro estabelecido no anexo XX da Portaria de Consolidação 5/2017 do Ministério da Saúde, o resultado obtido foi 4,57, inferior ao valor determinado $(6,0$ a 9,5), apresentando 
alto potencial de dano ao sistema de irrigação. $\mathrm{O}$ valor baixo encontrado para o pH pode estar relacionado a profundidade do poço, conforme verificou os Azevedo et al. (2002) que registraram valores menor de pH em poços de menor profundidade (de $18 \mathrm{~m}$ a $20 \mathrm{~m}$ ).

Quadro 2: Resultados obtidos na análise físico-química.

\begin{tabular}{|l|l|l|}
\hline Parâmetro & Valor máximo permitido (VMP) & Unidade \\
\hline Cálcio & 0 & $\mathrm{mg} / \mathrm{L}$ \\
\hline Magnésio & 0 & $\mathrm{mg} / \mathrm{L}$ \\
\hline Dureza total & 0 & $\mathrm{mg} / \mathrm{L}$ \\
\hline Alcalinidade em $\mathrm{OH}_{-}$ & 0 & $\mathrm{mg} / \mathrm{L}$ \\
\hline Alcalinidade em $\mathrm{CO}_{3-}$ & 0 & $\mathrm{mg} / \mathrm{L}$ \\
\hline Alcalinidade em $\mathrm{HCO}_{3}-$ & 14 & $\mathrm{mg} / \mathrm{L}$ \\
\hline Alcalinidade total & 14 & $\mathrm{mg} / \mathrm{L} \mathrm{CaCO}$ \\
\hline Cloretos (Cl-) & 1,90 & $\mathrm{mg} / \mathrm{L}$ \\
\hline pH & 4,57 & - \\
\hline Turbidez & - & $\mathrm{uT}$ \\
\hline
\end{tabular}

De acordo com Von Sperling (2005) um pH ácido (menor que 7) possui um potencial corrosivo que agride tubulações e estão relacionados com a obstrução física dos sistemas de irrigação, vale informar que pH muito altos ou muito baixos são um indicativo de contaminação. É importante observar que, a Portaria de Consolidação 5/2017, não apresenta valores estipulados para a alcalinidade total, assim como também para outros parâmetros, como cálcio e magnésio. Acerca da alcalinidade total, encontrou-se com a análise a presença de alcalinidade na água $\left(14 \mathrm{mg} / \mathrm{L} \mathrm{CaCO}_{3}\right.$ ). A alcalinidade na água está relacionada há possíveis presenças de íons de bicarbonato, carbonatos e hidróxidos que podem provocar o entupimento de dispositivos de irrigação (aspersores).

Quanto a concentração de cloreto, notou-se que para o poço abastecedor (irrigador), apresentou-se bem abaixo do VMP (1,90 mg/L) do anexo XX da Portaria de Consolidação 5/2017 (250 mg/L). A respeito do cálcio e magnésio não se constatou a presença desses metais na água, o que corrobora a ausência de dureza na água. É valido informar que a dureza não apresenta importância sanitária, mas o uso de uma água para irrigação com excesso destes íons ocasiona especialmente em irrigação localizada, a formação de cristais no orifício de saída de água (bocal), que poderá obstruir a passagem e diminuir a vazão do emissor (NAKAYAMA et al., 1986).

De modo geral os parâmetros físico-químicos interferem mais diretamente no sistema de irrigação do que na qualidade da água, pois estes parâmetros, principalmente os químicos, estão ligados à obstrução física das tubulações e emissores devido a alguns íons sofrerem reações de precipitação ou oxidação, ou mesmo a deposição de partículas minerais, como argila, aumentando, assim, a perda de carga e diminuindo a vida útil do sistema (HERNANDEZ, 2001). No tocante da análise biológica, os resultados obtidos deste parâmetro encontram-se no quadro 3.

Quadro 3: Resultados obtidos na análise biológica.

\begin{tabular}{|l|l|l|}
\hline Parâmetro & Valor máximo permitido (VMP) & Unidade \\
\hline Coliformes totais & $<1,0 \mathrm{NPM} / 100 \mathrm{~mL}$ & $\mathrm{~mL}$ \\
\hline E. coli & $<1,0 \mathrm{NPM} / 100 \mathrm{~mL}$ & $\mathrm{~mL}$ \\
\hline Bactérias heterotróficas & 100 & $\mathrm{UFC} / \mathrm{mL}$ \\
\hline
\end{tabular}

A partir dos resultados dos parâmetros biológicos investigados, constata-se que a amostra de água 
analisada apresentou qualidade higiênicos sanitária satisfatória, pois atendeu os padrões microbiológicos vigentes estabelecidos no anexo XX da Portaria de Consolidação 5/2017. Pontou-se que, o Conselho Nacional de Meio Ambiente (CONAMA) através da Resolução no 396/2008, que dispõe sobre a classificação e diretrizes ambientais para o enquadramento das águas subterrâneas, não estabelece limites máximos para os parâmetros microbiológicos quanto ao uso da água subterrânea para fins de irrigação (BRASIL, 2008).

Pacheco et al. (2002) alertam que as águas destinadas à irrigação são fontes originais de contaminação quando comportam grande quantidade de microrganismos como coliformes de origem fecal, aeromonas, salmonelas, parasitas intestinais e outros, portanto alimentos que estão em contato direto com estas águas contaminadas e se consumidos crus constituem fontes prováveis de intoxicação alimentar. É importante registrar que o solo atua como um filtro natural para degradação de muitos contaminantes, reduzindo os riscos de poluição nas águas subterrâneas, mas além disso ressalta-se que a prática da agricultura orgânica nessa área, evita claramente a poluição química das águas subterrâneas.

\section{CONCLUSÕES}

De acordo com os resultados obtidos neste trabalho, pode-se concluir que a água utilizada para irrigação no Hort Canaã apresentou pH ácido $(4,57)$ que pode estar relacionado a profundidade do poço e que acarreta problemas físicos ao sistema de irrigação, contudo não contamina os produtos cultivados; a concentração de cloreto apresentou-se abaixo do VMP do anexo XX da Portaria de Consolidação 5/2017. Não se constou presença de magnésio e cálcio na amostra de água, logo notou-se que há ausência de dureza na água; e a amostra de água analisada atendeu os padrões microbiológicos vigentes.

Em virtude do que foi mencionado, tem-se que as amostras de água analisadas, de um modo geral, têm uma boa qualidade para fins de irrigação das culturas orgânicas produzidas no Hort Canaã. Para resultados mais precisos torna-se necessário a realização do acompanhamento (do monitoramento) dos parâmetros indicadores de qualidade da água de irrigação durante o período seco e chuvoso.

\section{REFERÊNCIAS}

APHA. American Public Health Association. Standart methods for the examination of water and wastewater. 20 ed. Washington: APHA, 1998.

AYERS, R. S.; WESTCOT, D. W. A qualidade da água na agricultura. 2 ed. Campina Grande: UFPB, 1999.

BRASIL. Ministério da Saúde (MS). Anexo XX da Portaria de Consolidação 5, de 28 de setembro de 2017. Dispõe sobre normas de potabilidade de água para o consumo humano. Brasília: SVS, 2017.

CONAMA. Conselho Nacional de Meio Ambiente. Resolução no 396, de 03/04/2008. Dispõe sobre a classificação e diretrizes ambientais para o enquadramento das águas subterrâneas e dá outras providências. Brasília: CONAMA, 2008.

ENDLER, D. T. K.; NOGUEIRA, P. C.; SANTANA, V. S.; FIORESES, M. L.; HASAN, S. D. M.. Avaliação da qualidade da água de irrigação utilizada em propriedades rurais do município de Toledo-PR. In: ENCONTRO PARANAENSE DE ENGENHARIA E CIÊNCIA, 3. Anais. Toledo: Unioeste, 2013. p.45-51.

FROEHNER, S.; MARTINS, R. F.. Avaliação da composição química de sedimentos do Rio Birigui na Região metropolitana de Curitiba. Química Nova, v.31, p.20202026, 2008.

HERNANDEZ, F. B. T.. Qualidade de água em um sistema irrigado no noroeste paulista. In: CONGRESSO BRASILEIRO DE ENGENHARIA AGRÍCOLA, 10. Anais. Foz de Iguaçu, 2001.

LIMA, E. B. N. R.. Modelagem Integrada para Gestão da Qualidade da Água na Bacia do Rio Cuiabá. Tese (Doutorado) - Universidade Federal do Rio de Janeiro, Rio de Janeiro, 2001.

MENDES, D. C. T.. O abastecimento de água para consumo 
humano na área urbana de São Luís: onde está a qualidade?. Dissertação (Mestrado em Saúde e Ambiente) Universidade Federal do Maranhão, São Luís, 2008.

NAKAYAMA, F. S.; BUCKS, D. A.. Trickle irrigation for crop production. St. Joseph: ASAE, 1986.

OLIVEIRA, C. A. F., GERMANO, P. M. L.. Estudo da ocorrência de enteroparasitas em hortaliças comercializadas na região metropolitana de São Paulo/SP, Brasil. II - Pesquisa de protozoários intestinais. Revista de Saúde Pública, São Paulo, v.26, n.5, 1992.
PACHECO, M. S. R.; FONSECA, Y. S. K.; DIAS, H. G. G.; CÂNDIDO, V. L. P.; GOMES, A. H. S.; ARMELIN, I. M.

BERNARDES, R.. Condições higiênicos-sanitárias de verduras e legumes comercializadas no CEAGESP de Sorocaba/SP. Higiene Alimentar, São Paulo, v.16, n.101, p.50-51, 2002.

SILVA, A. B. A.; UENO, M.. Qualidade sanitária das águas do rio Una, São Paulo, Brasil, no período das chuvas. Revista Biociências, Taubaté, v.14, n.1, p.82-86, 2008.

VON SPERLING, M.. Introdução à qualidade da água e ao tratamento de esgotos. 3 ed. Belo Horizonte: DESA, 2005.

A CBPC - Companhia Brasileira de Produção Científica (CNPJ: 11.221.422/0001-03) detém os direitos materiais desta publicação. Os direitos referem-se à publicação do trabalho em qualquer parte do mundo, incluindo os direitos às renovaç̃ões, expansões e disseminações da contribuição, bem como outros direitos subsidiários. Todos os trabalhos publicados eletronicamente poderão posteriormente ser publicados em coletâneas impressas sob coordenação da Sustenere Publishing, da Companhia Brasileira de Produção Científica e seus parceiros autorizados. Os (as) autores (as) preservam os direitos autorais, mas não têm permissão para a publicação da contribuição em outro meio, impresso ou digital, em português ou em tradução. 